\title{
Age and gender differences in half-Ironman triathlon performances - the Ironman 70.3 Switzerland from 2007 to 2010
}

This article was published in the following Dove Press journal:

Open Access Journal of Sports Medicine

17 July 2012

Number of times this article has been viewed

\author{
Beat Knechtle ${ }^{1,2}$ \\ Christoph Alexander Rüst ${ }^{2}$ \\ Thomas Rosemann ${ }^{2}$ \\ Romuald Lepers ${ }^{3}$ \\ 'Gesundheitszentrum St Gallen, \\ St Gallen, Switzerland; ${ }^{2}$ Institute \\ of General Practice and Health \\ Services Research, University \\ of Zurich, Zurich, Switzerland; \\ ${ }^{3}$ INSERM UI 093, Faculty of Sport \\ Sciences, University of Burgundy, \\ Dijon, France
}

Background: To date, the age-related decline and gender differences in performance have been investigated for both Olympic and Ironman distance triathlons, but not for the intermediate distance (ie, the half-Ironman distance triathlon covering $1.9 \mathrm{~km}$ swimming, $90 \mathrm{~km}$ cycling and $21.1 \mathrm{~km}$ running, Ironman $70.3^{\circledR}$ ). We determined the age-related differences in performance and the gender differences for female and male half-Ironman triathletes of 6303 finishers (1115 women and 5188 men) at the Ironman 70.3 Switzerland in Rapperswil, Switzerland, from 2007 to 2010.

Methods: Analyses of variance were used to examine performance trends and differences between the genders.

Results: Gender differences in total event time were affected by age $(\mathrm{F}=4.2 ; P<0.001)$. Women achieved their best performance between 25 and 39 years whereas men attained their fastest race times between 18 and 39 years. The gender difference for ages 18-24 years was significantly $(P<0.01)$ greater compared to older age groups (25-29 years and 40-44 years), and the gender difference for age groups $45-49$ years and $50-54$ years was significantly $(P<0.01)$ greater than for those between the ages of 35-39 years.

Conclusion: The present data suggest that the fastest race time in a half-Ironman triathlon was achieved between the age of 25 and 39 years for women and between 18 and 39 years for men. Further studies considering the influences on endurance performance are required to better understand the age and gender interactions in half-Ironman triathlon performances, and these studies may provide valuable information to delineate the difference in performance between female and male half-Ironman triathletes.

Keywords: cycling, endurance, female, male, running, swimming

\section{Introduction}

The sports triathlon involves successively completing the three single endurance disciplines: swimming, cycling, and running. The traditional race distances in triathlon vary from the short or Olympic distances involving $1.5 \mathrm{~km}$ swimming, $40 \mathrm{~km}$ cycling, and $10 \mathrm{~km}$ running, ${ }^{1-3}$ to the Ironman distances involving $3.8 \mathrm{~km}$ swimming, $180 \mathrm{~km}$ cycling, and $42.2 \mathrm{~km}$ running. ${ }^{5-8}$ Several studies in recent years have focused on analyzing factors affecting performance in both the Olympic and the Ironman distance triathlon. Regarding triathlon performance, a number of factors have been investigated in terms of how these relate to overall race time. These factors have included different characteristics in anthropometry, ${ }^{9,10,12,13}$ physiology, ${ }^{17,18}$ training,,${ }^{9,10,19}$ previous experience, ${ }^{9,12,20-22}$ and age. ${ }^{1-4}$ An age-related decline in performance has been described for both the Olympic distance ${ }^{1-7}$ and Ironman distance triathlons. ${ }^{6.8}$ For example, Lepers
Correspondence: Beat Knechtle Facharzt FMH für Allgemeinmedizin, Gesundheitszentrum St Gallen, Vadianstrasse 26,900I St Gallen, Switzerland

Tel +4I 07I 2268282

Fax +4| 07| 2268272

Email beat.knechtle@hispeed.ch which permits unrestricted noncommercial use, provided the original work is properly cited. 
and Maffiuletti reported a gender difference for the fastest race performance in an Ironman triathlon. ${ }^{7}$ Male Ironman triathletes achieved their fastest race between the ages of 30 and 34 years and 35 and 39 years, whereas females performed their fastest between the ages of 25 and 29 years and 30 and 34 years. $^{7}$

The pattern of the age-related changes in triathlon performance depends on (1) locomotion mode, (2) distance, and (3) gender. ${ }^{1,3,4,7}$ Bernard et al showed that for male Olympic distance triathletes, a decline in performance times across the three disciplines was associated with advancing age in a curvilinear manner; however, the pattern of decline was specific for each locomotion mode. ${ }^{1}$ In the Olympic distance triathlon, the decline in performance was more pronounced during swimming and running, whereas performance remained fairly stable during cycling irrespective of age. Lepers et al compared the age-related performance decline between both male Olympic distance triathletes and male Ironman triathletes. ${ }^{3}$ They described a lower age-related decline in cycling performance compared to running and swimming after the age of 55 years for the Olympic distance and after the age of 50 years for the Ironman distance. With advancing age, the performance decline was less pronounced in the Olympic distance triathlon than in the Ironman triathlon in cycling ( $>55$ years) and running ( $>50$ years), respectively. ${ }^{3}$

To date, the age-related decline and gender difference in performance have been investigated for both Olympic and Ironman distance triathlons, but not for the intermediate distance (ie, the half-Ironman [Ironman $70.3^{\circledR}$ ] triathlon covering $1.9 \mathrm{~km}$ swimming, $90 \mathrm{~km}$ cycling, and $21.1 \mathrm{~km}$ running). Currently, there are 50 Ironman 70.3 races offered around the World. ${ }^{24}$ This distance is of increasing popularity because tens of thousands of athletes are interested in qualifying for the Ironman World Championship $70.3^{25}$ held since 2008. Considering the Olympic distance triathlon as a baseline, the distances for the split disciplines do not increase in a linear manner for Ironman 70.3 and Ironman. The lengths for each of the disciplines from the Olympic distance triathlon to the Ironman distance exhibit an increase in completion times for both cycling and running, and this is particularly associated with an increase in length of the triathlon distance.

With the increasing length of endurance performance, a greater difference in the decline of the performance may occur between the genders. If we consider the Ironman performance as the gold standard, the reduced length of endurance performance associated with the half-Ironman distance might also attenuate the gender difference. ${ }^{7}$ Regarding the gender difference in performance for the split disciplines among Ironman triathletes and off-road triathletes, the mean gender difference in swimming is not as drastic as compared to the gender differences noted in cycling and running. ${ }^{2,7}$ One explanation for these differences between locomotion modes is the higher economy and mechanical efficiency of swimming in women compared to men. The higher mechanical efficiency of women has been attributed to a smaller body size (resulting in a smaller body drag), a smaller body density (greater fat percent), and shorter lower limbs, resulting in a more horizontal and streamlined position, and therefore results in a smaller underwater torque. ${ }^{7}$

It has been shown that among Ironman triathletes, the gender difference in total event performance time increased significantly with advancing age after 55 years. ${ }^{7}$ The exact reasons for these sex-related differences are not clear but could be due to a greater decline of one or more physiological determinants of endurance performance for women compared to men (eg, maximal oxygen uptake, lactate threshold, and exercise economy). Also differences in anthropometry may lead to different performances in swimming, cycling, and running, affecting the length of endurance performance in accordance with gender. Female Ironman triathletes have reduced skeletal muscle mass and higher body fat compared to male Ironman triathletes. ${ }^{9-11,27}$ Gender differences in anthropometric characteristics such as body fat have also been found to affect triathletes' halfIronman race performance. ${ }^{8,9}$

In this context, the first aim of this study was to determine the age-related changes in performance and the gender difference in half-Ironman triathlon performances. We hypothesized that (1) the age-related decline in performance would be greater in females when compared to males; and (2) the gender difference would differ among the three disciplines. The second aim was to determine the age of the fastest performance in male and female half-Ironman triathletes. Regarding recent findings pertaining to Ironman triathletes, we hypothesized that the females would achieve their fastest race time at a younger age when compared to the males. To test this hypothesis, we investigated age- and gender-related differences in overall and split performances in male and female athletes competing in Ironman 70.3 Switzerland covering $1.9 \mathrm{~km}$ swimming, $90 \mathrm{~km}$ cycling, and $21 \mathrm{~km}$ running from 2007 to 2010. 


\section{Methods}

This study was approved by the Institutional Review Board of St Gallen, Switzerland, with waiver of the requirement for informed consent given that the study involved the analysis of publicly available data. The data set from this study was obtained from the race website ${ }^{26}$ and from the race director (M Koller, email communication, 6 June, 2010). Ironman $70.3^{\circledR}$ is the other name for the half-Ironman distance triathlon where 70.3 corresponds with the total distance of the halfIronman triathlon, expressed in miles. ${ }^{24}$

Since 2007, Ironman 70.3 Switzerland, covering $1.9 \mathrm{~km}$ swimming, $90 \mathrm{~km}$ cycling, and $21 \mathrm{~km}$ running, has been held each year in the city of Rapperswil during the month of June. The swimming event is held as one $1.9 \mathrm{~km}$ loop in Lake Zurich. For cycling, the athletes complete two laps of $45 \mathrm{~km}$ each. While starting at $400 \mathrm{~m}$ of altitude, they have to climb a $700 \mathrm{~m}$ hill twice. Drafting is forbidden. The running event involves having each triathlete complete two laps in the city of Rapperswil. During the cycling event, the organizer offers a total of six aid stations, while during the running event, a total of 14 aid stations provide water, hypotonic sports drinks, caffeinated drinks, fruit, energy bars, and energy gels for the triathletes.

In Ironman $70.3,{ }^{24}$ the following age groups are distinguished: 18-24 years, 25-29 years, 30-34 years, 35-39 years, $40-44$ years, $45-49$ years, $50-54$ years, $55-59$ years, 60-64 years, and 65-69 years. First, triathletes' ages and performance times for swimming, cycling, running, and the total race were analyzed from 2007 to 2010 . The data were analyzed from a total of five female and five male finishers at Ironman 70.3 Switzerland. Second, swimming, cycling, running, and total performance times of the top five of ten age groups for males (ie, 18-24 years, 25-29 years, 30-34 years, 35-39 years, 40-44 years, 45-49 years, 50-54 years, 55-59 years, 60-64 years, and 65-69 years) and the top seven age groups for females (ie, 18-24 years, 25-29 years, 30-34 years, 35-39 years, 40-44 years, 45-49 years, and 50-54 years) were analyzed for the same period (2007-2010 inclusive) due to the lower number of female participants.

\section{Data analysis}

\section{Top five females and males overall}

One-way analysis of variance (ANOVA) showed that the mean time performance for the top five female and five male finishers was not statistically different between 2007 and 2010, so we pooled four years of data. Data (ie, triathletes' ages, and performance times across swimming, cycling, running, and the overall race) were averaged across the first five female and male finishers for each year from 2007 to 2010. Therefore, the performances of 80 triathletes (ie, the top five female and top five male finishers for each of the four years) were considered. Swimming, cycling, running, and total performance times were converted to minutes. The magnitude of the gender difference was examined by calculating the percent difference for the swimming, cycling, running, and total times of the top five female athletes versus the top five male athletes.

\section{Top five females and males of each age group}

One-way ANOVA showed that the mean total performance times of the top five male and the top five female triathletes of each age group were not statistically different between the years from 2007 to 2010 , so we pooled the four years of data. Therefore, the performances of 20 triathletes per age group (ie, the top five triathletes in each age group for four years) were considered. The magnitude of the gender difference was examined by calculating the percent difference for the swimming, cycling, running, and total times of the top five female triathletes versus the top five male triathletes of each age group.

\section{Statistical analysis}

Kolmogorov-Smirnov tests were conducted before statistical analysis and confirmed that all data were normally distributed. Data are reported as means \pm standard deviation (SD) in the text. One-way ANOVA (Statsoft, Version 6.1; Statistica, Tulsa, OK) was used to compare (1) the age of the top five male and female finishers across the four years, (2) the swimming, cycling, running, and total times across each of the age groups for both males and females, and (3) the gender difference in total time across the age groups. Two-way ANOVAs (age group $\times$ mode of locomotion) with repeated measures on locomotion mode were used to compare the gender difference in time between swimming, cycling, and running across age groups. Tukey's post hoc analyses were used to test the differences within the ANOVAs when appropriate. A significance level of $P<0.05$ was considered to be statistically significant.

\section{Results}

From 2007 to 2010, there were 6303 total finishers (1115 females and 5188 males) in the Ironman 70.3 Switzerland triathlon. Females accounted for an average of $18.0 \% \pm 1.9 \%$ of the triathletes since 2007. The age distribution of the finishers from 2007 to 2010 is displayed in Figure 1. 


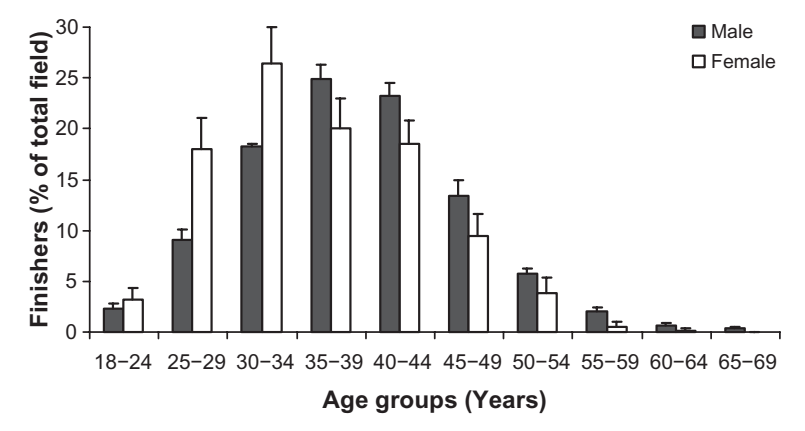

Figure I Age distribution (mean $\pm S D$ ) of male and female finishers from 2007 to 2010 (pooled data) at the Ironman $70.3^{\circledR}$ Switzerland. ${ }^{36}$

The 5-year age bracket with the greatest participation rates was 30-34 years for females and 35-39 years for males.

The performance times of the top five female finishers were significantly $(P<0.01)$ greater compared to their male counterparts for swimming, cycling, running, and total event (Table 1). The mean age of the top five male finishers was not significantly different when compared to the top five female finishers $(P>0.05)$. The gender differences in performance times were not statistically different between the different modes of locomotion across the total event and ranged from $12.3 \%$ to $14.1 \%(P>0.05)$.

The swimming, cycling, running, and total performance times of the top five female and top five male athletes from each age group are presented in Figure 2. The performance times across each of the three disciplines and for the total event increased in a curvilinear manner with advancing age. There was a significant $(P<0.0001)$ age effect on swimming, cycling, running, and total event performance times for both females and males. For males, no significant difference in performance time was observed among triathletes between the ages of 18-24 years and 35-39 years for swimming; between the ages of 25-29 years and 35-39 years for cycling; between the ages of 18-24 years and 40-44 years for running; and between the ages of 18-24 years and 35-39 years

Table I Age, swimming, cycling, running, and total performance times for the top five males and top five females, and corresponding gender differences at the Ironman $70.3^{\circledR}$ Switzerland (2007 to 2010 pooled data) ${ }^{36}$

\begin{tabular}{llll}
\hline & Males & Females & $\begin{array}{l}\text { Gender } \\
\text { difference (\%) }\end{array}$ \\
\hline Age (years) & $30.2 \pm 4.5$ & $31.7 \pm 4.2$ & $3.2 \pm 19.3$ \\
$1.9 \mathrm{~km} \mathrm{swim}(\mathrm{min})$ & $24.5 \pm 1.4$ & $28.7 \pm 2.8^{*}$ & $14.1 \pm 9.0$ \\
$90 \mathrm{~km}$ cycle (min) & $134.1 \pm 3.5$ & $153.1 \pm 6.2^{*}$ & $12.3 \pm 3.2$ \\
$21 \mathrm{~km}$ run (min) & $78.5 \pm 2.9$ & $89.8 \pm 4.3^{*}$ & $12.5 \pm 4.2$ \\
Total (min) & $238.9 \pm 5.4$ & $273.6 \pm 9.6^{*}$ & $12.6 \pm 1.8$ \\
\hline
\end{tabular}

Notes: Values are mean \pm SD. *Significantly different from males, $P<0.001$. for the total event. For females, no significant difference in performance time was observed among triathletes between the ages of 25-29 years and 35-39 years for swimming, cycling, running, and the total event.

The difference in performance expressed as a percentage between the different age groups and the fastest male or female age group for swimming, cycling, running, and total time are presented in Table 2. Compared to the fastest male's age group (30-34 years), time performance of the slowest male's age group (65-69 years) was longer for the total event (62.3\%), as well as for the swimming (91.2\%), cycling (44.4\%), and running (77.5\%) events. Compared to the fastest female's age groups (30-34 years or 35-39 years), time performance of the slowest female's age group (50-54 years) was longer for the total event (23.3\%), as well as the swimming (34.0\%), cycling (17.8\%), and running (29.3\%) events. For both males and females, there was a reduced age-related decline in cycling performance when compared with running and swimming performance.

There was no significant age group $\times$ locomotion mode interaction for gender difference in performance time $(\mathrm{F}=0.96$; $P=0.48)$. The gender differences in time differed between the locomotion modes $(\mathrm{F}=7.34 ; P<0.001)$ and was independent of age. The gender difference in swimming time was significantly greater than for cycling $(P<0.01)$ (Figure 3$)$.

Figure 4 shows that the gender differences in the total event time were affected by age $(\mathrm{F}=4.2 ; P<0.001)$. The gender difference for triathletes between the ages of 18-24 years was significantly $(P<0.01)$ greater when compared to triathletes who fell in the older age groups of 25-29 years and 40-44 years. Moreover, gender difference in performance times for triathletes falling in the age groups of 45-49 years and 50-54 years was significantly greater than for the 35-39 age group $(P<0.01)$.

\section{Discussion}

The main findings were (1) the age-related differences in halfIronman performances differed between males and females; (2) the gender differences differed between the locomotion mode; (3) the gender difference in total time differed across age groups; and (4) the best performances across all split times and overall race time were achieved by triathletes falling between the ages of 25 and 39 years for females and between 18 and 39 years for males.

The present study demonstrated a curvilinear relationship of performance with advancing age for half-Ironman distance triathlon. It was noted that after the age of 40 years, triathletes of both genders demonstrated age-related performance 

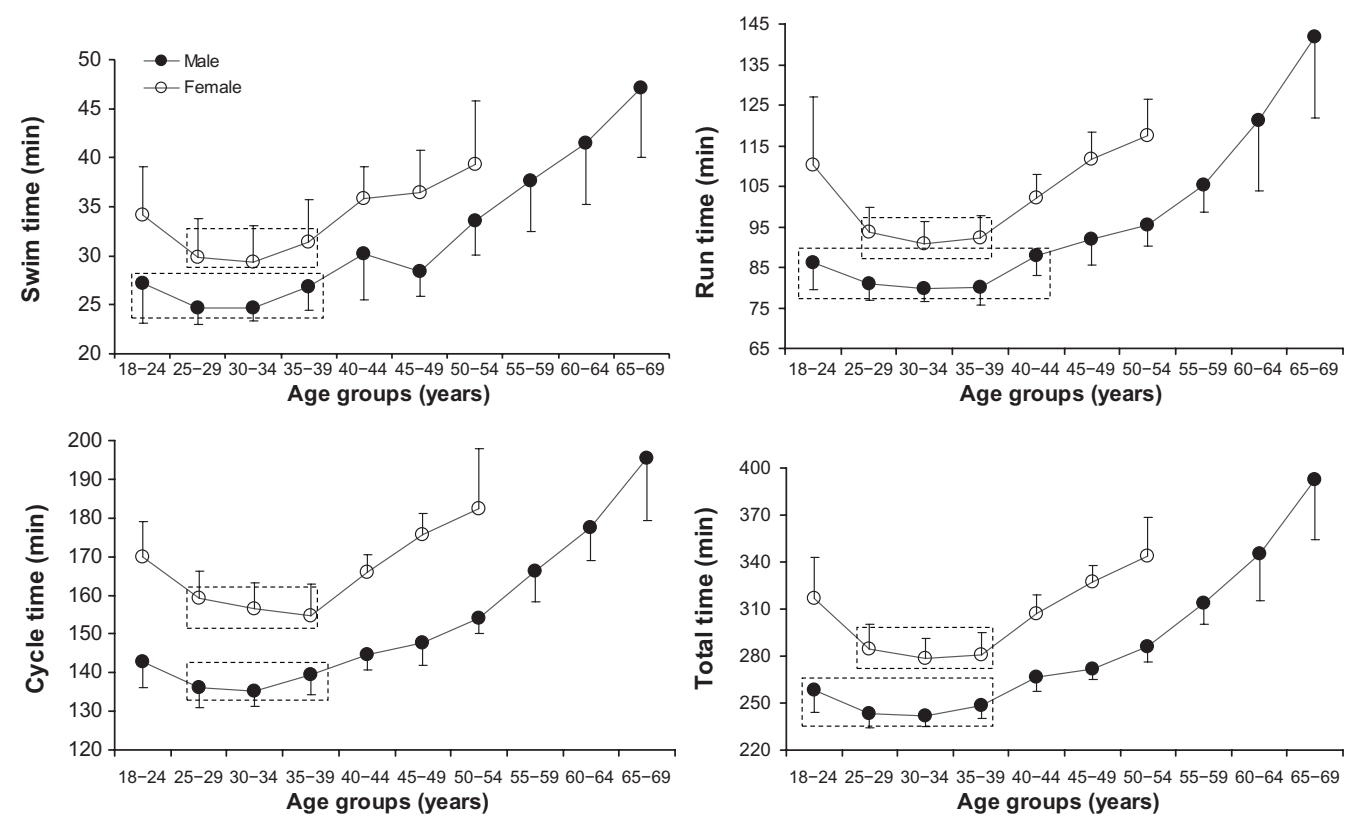

Figure 2 Swimming, cycling, running, and total performance times for the top five males and females in each age group at the Ironman $70.3^{\circledR}$ Switzerland (2007 to 2010 pooled data). ${ }^{36}$

Notes: The values inside the dotted line square are not significantly different from each other. Values are presented as mean \pm SD.

declines; this difference was fairly consistent, except that performance declines for males in the running event began at 45 years. This finding differs slightly from those of previous studies that investigated age-related performance declines in both Olympic distance and Ironman triathlons. ${ }^{1,3,4}$ For example, it was found that for the Olympic distance, triathletes' performance began to decrease from 40 years for swimming, from 50 years for running, and from 55 years for cycling. ${ }^{3}$ For the Ironman distance, the performance started to decrease from 45 years for swimming and running, and from 50 years for cycling. ${ }^{3}$ This earlier decline in performance among triathletes in the half-Ironman distance when compared to either the Olympic or Ironman distances may be related to the race level, as the half-Ironman may be considered a national level triathlon, while the Olympic and Ironman distances are considered to be world championships. In this race, athletes at national level competed. The best triathletes of older age groups ( $>40$ years) competing at world level may have a better level compared to athletes competing at national level. ${ }^{4}$ This might explain the later age-related decline in performance reported for both Olympic and Ironman distances. ${ }^{1,3,4}$ However, the present findings confirm that the age-related decline in cycling performance is reduced when compared with performance times for the running and swimming events in the half-Ironman distance triathlon; this was also observed across the Olympic and Ironman distances. ${ }^{1,2,3,7}$

Gender differences in performance time varied as a function of the locomotion mode. ${ }^{1,2,3,7}$ The gender differences in cycling (16\%) and running (19\%) observed in the present study for half-Ironman triathletes are similar to those found for Ironman triathletes. ${ }^{7}$ For Ironman triathletes, the gender difference was less pronounced in the swimming event (12\%)

Table 2 Differences in performance (expressed as percentages) between the different age groups and the fastest male's or female's age group (value $=0)$ for swimming, cycling, running, and total time in the Ironman $70.3^{\circledR}$ Switzerland $(2007 \text { to } 2010 \text { pooled data })^{36}$

\begin{tabular}{|c|c|c|c|c|c|c|c|c|c|c|c|}
\hline & & \multicolumn{10}{|c|}{ Age groups (years) } \\
\hline & & $18-24$ & $25-29$ & $30-34$ & $35-39$ & $40-44$ & $45-49$ & $50-54$ & $55-59$ & $60-64$ & $65-69$ \\
\hline \multirow[t]{4}{*}{ Females } & Swimming & 16.5 & 1.9 & 0 & 6.8 & 22.3 & 24.4 & 34.0 & & & \\
\hline & Cycling & 9.8 & 2.8 & I.I & 0 & 7.1 & 13.5 & 17.8 & & & \\
\hline & Running & 21.3 & 3.0 & 0 & 1.6 & 12.3 & 23.0 & 29.3 & & & \\
\hline & Total & 13.7 & 2.2 & 0 & 0.8 & 10.1 & 17.5 & 23.3 & & & \\
\hline \multirow[t]{4}{*}{ Males } & Swimming & 10.3 & 0 & 0 & 9.1 & 22.3 & 15.4 & 36.1 & 52.5 & 68.4 & 91.2 \\
\hline & Cycling & 5.6 & 0.6 & 0 & 3.1 & 6.8 & 9.1 & 13.8 & 22.8 & 31.1 & 44.4 \\
\hline & Running & 8.0 & 1.2 & 0 & 0.4 & 10.1 & 15.2 & 19.7 & 31.7 & 51.7 & 77.5 \\
\hline & Total & 6.9 & 0.7 & 0 & 2.9 & 10.2 & 12.4 & 18.4 & 29.7 & 42.9 & 62.3 \\
\hline
\end{tabular}




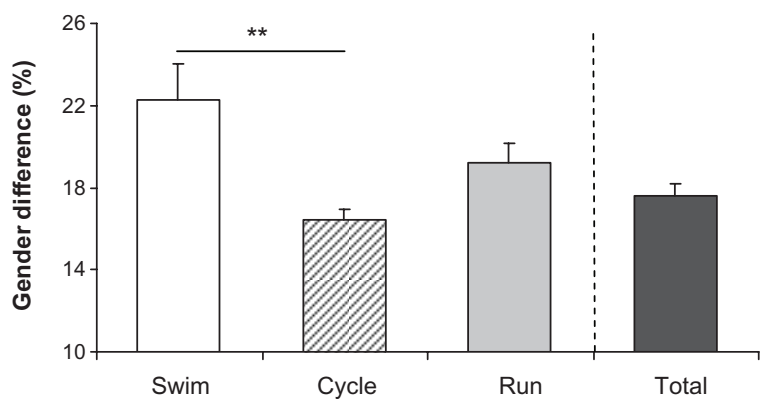

Figure 3 Averaged gender difference in time performance for swimming, cycling, running, and total event across all age groups (18-24 years to 50-54 years) in Ironman $70.3^{\circledR}$ Switzerland (2007 to 2010 pooled data). ${ }^{36}$

Notes: Values are presented as mean \pm SE. **Significantly different from swimming, $P<0.0$ I.

Abbreviation: SE, standard error.

when compared to performance in the cycling (15\%) and running (18\%) events. ${ }^{7}$ In contrast, the present study reported a greater gender difference in swimming $(22 \%)$ when compared to the Ironman distance. This result was unexpected and the mechanisms underlying this difference are unclear. It has been suggested that females might be exhibiting a higher swimming efficiency than males due to their smaller body size (resulting in a smaller body drag), a smaller body density (greater fat percent), and shorter lower limbs, resulting in a more horizontal and streamlined position and therefore creating reduced underwater torque. ${ }^{28}$ Thus females might demonstrate a greater advantage in the $3.8 \mathrm{~km}$ than in $1.9 \mathrm{~km}$ half-Ironman distance swimming event.

Gender difference in lower limb muscle mass may also account for the gender differences in performance times. In cycling, the main factor accounting for gender differences in peak and mean power output during cycling is the muscle mass of the lower extremities..$^{29,30}$ Males show a greater peak power output in cycling when compared to females.

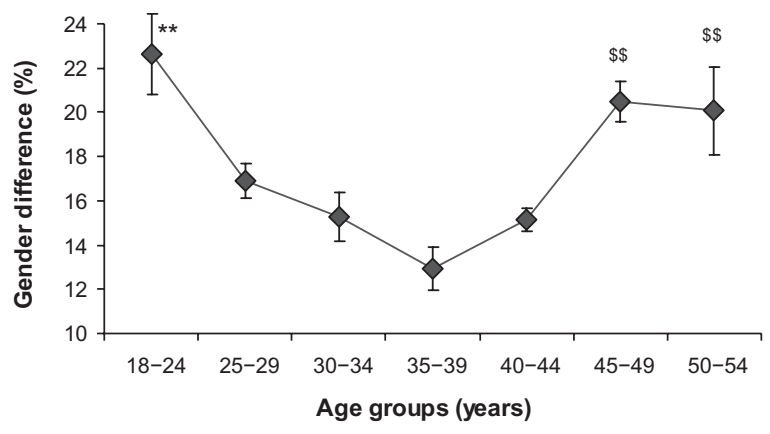

Figure 4 Averaged gender difference in time for total event at the Ironman $70.3^{\circledR}$ Switzerland ( 2007 to 2010 pooled data). ${ }^{36}$

Notes: Values are presented as mean \pm SE. **Significantly different from all age groups from $25-29$ to $40-44$ years, $P<0.01$. ${ }^{\$ S}$ Significantly different from age group 35-39 years, $P<0.01$.

Abbreviation: SE, standard error.
In addition, both lean leg volume and lean upper leg volume are greater in males than in females. ${ }^{30}$ Doré et al investigated the gender-related differences in maximal leg muscle power in females and males between the ages of 8 and 20 years. ${ }^{31}$ From the age of 16 years, males showed a greater cycling peak power for lean leg volume than females. Apart from anthropometric characteristics, physiological characteristics may also explain the gender difference in performance. In triathletes, physiological differences that affect performance during the cycling and running events may affect overall race performance. ${ }^{32,33}$ Sleivert and Wenger investigated performance differences among male and female Olympic distance triathletes, and they found that swimming performance was related to the relative maximum oxygen uptake in both males and females, while running performance was related to the relative maximum oxygen uptake in females, and velocity while running at the ventilatory threshold was related to performance in both males and females. ${ }^{34}$ Relative maximum oxygen uptake while swimming, overall velocity in running at ventilatory threshold, and absolute leg flexion strength were related to overall performance times in females. For males, the only significant predictor of overall race time was velocity in running at ventilatory threshold. They concluded that the physiological variables involved in swimming and running are important contributors to overall race time in Olympic distance triathletes. These different physiologic findings may explain the gender-related differences in swimming, running, and overall race times in the 18-24 age group among the half-Ironman triathletes analyzed in the current study.

Interestingly, we observed a greater gender difference in total performance times for the 18-24 age group and for the older age groups (45-49 years and 50-54 years) when compared to the 25-44 age group. The exact reasons for these sex-related differences among the older age groups are not clear, but they could be associated with a greater decline in one or more of the physiological determinants involved in endurance performance for women when compared to men (eg, maximal oxygen uptake, lactate threshold, and exercise economy). However, the age-related changes in the physiological determinants of endurance and ultraendurance performances between men and women have not received considerable attention. In addition, the greater gender difference for the youngest age group (ie, 18 to 24 years) was not expected and contrasts with previous findings found among Ironman triathletes, where the gender difference in total event time significantly increased as a function of increasing age ( $>55$ years). ${ }^{7}$ We hypothesized that young female triathletes racing at a national level 
race, like the Ironman 70.3 Switzerland race, had greater experience performing at races of this level than their male counterparts.

The ages associated with the fastest performance times for male and female half-Ironman triathletes differed slightly from the findings of Ironman triathletes. At the Ironman Hawaii, the fastest men's age group was 30-39 years whereas the fastest women's age group was 25-34 years. ${ }^{7}$ Male triathletes seem to perform their best at younger ages in the halfIronman distance triathlon when compared to the Ironman distance triathlon. In contrast, female triathletes appear to perform their best at similar ages for both distances. The agerelated peak performance time discrepancies noted among males and females for the half- and full-Ironman triathlon distances need further investigation.

\section{Methodological considerations}

In the present study, we did not verify or account for the number of triathletes that competed and placed in the top five of their age groups for more than 1 year. We cannot assure that the age-related performance decline is not at least partly due to the nonparticipation of older athletes, or whether this was a function of older athletes choosing to perform at a lower intensity. In addition, race participants may represent selected subgroups of the total population of half-Ironman triathletes. For example, some potential participants may have been prevented from participating due to many reasons. It was not possible to control for the factors that may have influenced triathlon performance such as environmental conditions, triathlete training, anthropometry, and previous experience in triathlon racing. , $^{910,35}$

\section{Conclusion}

The present findings observed at the Ironman 70.3 Switzerland confirm the reduced age-related decline in cycling performance when compared with running and swimming performance for half-Ironman distance triathlon. According to previous investigations and the present finding, it appears that the gender differences in triathlon event performance differed between the locomotion modes and between the triathlon distances. The fastest race time in a half-Ironman triathlon was achieved between the ages of 25 and 39 years for females and between the ages of 18 and 39 years for males. Further investigations of training status, physiological parameters, and race experience are required in order to better understand the age and gender interactions in half-Ironman triathlon performances.

\section{Acknowledgment}

We thank Matthias Knechtle for his help in translation.

\section{Disclosure}

The authors report no conflicts of interest in this work.

\section{References}

1. Bernard T, Sultana F, Lepers R, Hausswirth C, Brisswalter J. Age-related decline in olympic triathlon performance: effect of locomotion mode. Exp Aging Res. 2010;36(1):64-78.

2. Lepers R, Stapley PJ. Differences in gender and performance in off-road triathlon. J Sports Sci. 2010;28(14):1555-1562.

3. Lepers R, Sultana F, Bernard T, Hausswirth C, Brisswalter J. Agerelated changes in triathlon performances. Int J Sports Med. 2010; 31(4):251-256.

4. Stiefel M, Knechtle B, Lepers R. Master triathletes have not reached limits in their Ironman triathlon performance. Scand J Med Sci Sports. 2012 May 14 [Epub ahead of print].

5. Lepers R, Rüst CA, Stapley PJ, Knechtle B. Relative improvements in endurance performance with age: evidence from 25 years of Hawaii Ironman racing. Age (Dordr). 2012 Feb 26 [Epub ahead of print].

6. Lepers R. Analysis of Hawaii ironman performances in elite triathletes from 1981 to 2007. Med Sci Sports Exerc. 2008;40(10): 1828-1834.

7. Lepers R, Maffiuletti NA. Age and gender interactions in ultraendurance performance: insight from the triathlon. Med Sci Sports Exerc. 2011;43(1):134-139.

8. Knechtle B, Knechtle P, Lepers R. Participation and performance trends in ultra-triathlons from 1985 to 2009. Scand J Med Sci Sports. 2011;21(6):e82-e90.

9. Knechtle B, Wirth A, Baumann B, Knechtle P, Rosemann T. Personal best time, percent body fat, and training are differently associated with race time for male and female ironman triathletes. Res $Q$ Exerc Sport. 2010;81(1):62-68

10. Knechtle B, Wirth A, Baumann B, Knechtle P, Rosemann T, Oliver S. Differential correlations between anthropometry, training volume, and performance in male and female Ironman triathletes. $J$ Strength Cond Res. 2010;24(10):2785-2793.

11. Knechtle B, Wirth A, Baumann B, et al. An ironman triathlon does not lead to a change in body mass in female triathletes. Res Sports Med. 2010;18(2):115-126.

12. Knechtle B, Wirth A, Rosemann T. Predictors of race time in male ironman triathletes: physical characteristics, training, or prerace experience? Percept Mot Skills. 2010;111(2):437-446.

13. Knechtle B, Knechtle P, Rosemann T. Upper body skinfold thickness is related to race performance in male Ironman triathletes. Int $J$ Sports Med. 2011;32(1):20-27.

14. O'Toole ML. Training for ultraendurance triathlons. Med Sci Sports Exerc. 1989;21(5 Suppl):S209-S213.

15. O’Toole ML, Douglas PS, Hiller WD. Applied physiology of a triathlon. Sports Med. 1989;8(4):201-225.

16. O'Toole ML, Douglas PS, Hiller WD. Lactate, oxygen uptake, and cycling performance in triathletes. Int J Sports Med. 1989;10(6): 413-418.

17. Whyte G, Lumley S, George K, et al. Physiological profile and predictors of cycling performance in ultra-endurance triathletes. J Sports Med Phys Fitness. 2000;40(2):103-109.

18. Laursen PB, Knez WL, Shing CM, Langill RH, Rhodes EC, Jenkins DG. Relationship between laboratory-measured variables and heart rate during an ultra-endurance triathlon. J Sports Sci. 2005; 23(10):1111-1120.

19. Gulbin JP, Gaffney PT. Ultraendurance triathlon participation: typical race preparation of lower level triathletes. J Sports Med Phys Fitness. 1999;39(1):12-15. 
20. Rüst CA, Knechtle B, Knechtle P, Rosemann T, Lepers R. Personal best times in an Olympic distance triathlon and a marathon predict Ironman race time in recreational male triathletes. Open Access Journal of Sports Medicine. 2011;2:121-129.

21. Rüst CA, Knechtle B, Wirth A, et al. Personal best times in an Olympic distance triathlon and a marathon predict an Ironman race time for recreational female triathletes. Chin J Physiol. 2012 [Epub ahead of print]. Available from: http://www.cps.org.tw/docs/Vol55\%20No3E $\% 20$ Article\%202.pdf. Accessed 11 May, 2011.

22. Herbst L, Knechtle B, Lopez CL, et al. Pacing strategy and change in body composition during a deca iron triathlon. Chin J Physiol. 2011; 54(4):255-263.

23. Knechtle B, Knechtle P, Rosemann T, Senn O. Personal best time, not anthropometry or training volume, is associated with total race time in a triple iron triathlon. J Strength Cond Res. 2011;25(4):1142-1150.

24. IRONMAN.com [homepage on the Internet]. Ironman 70.3 race finder. World Triathlon Corporation (WTC), c. 2001-2012. Available from: http://ironman.com/events/ironman70.3. Accessed 10 August, 2010.

25. IRONMAN.com [homepage on the Internet]. Ironman Wold Championship 70.3. World Triathlon Corporation (WTC). World Triathlon Corporation (WTC), c. 2001-2012. Available from: http://ironman. com/events/ironman70.3/worldchampionship70.3. Accessed 10 August, 2010.

26. Ironman 70.3 Switzerland in Rapperswil-Jona [homepage on the Internet]. Rapperswil-Jona, Switzerland: World Triathlon Corporation (WTC); c2001-2012. Available from: http://ironmanrapperswil.com/. Accessed 10 August, 2010.

27. Knechtle B, Baumann B, Wirth A, Knechtle P, Rosemann T. Male ironman triathletes lose skeletal muscle mass. Asia Pac J Clin Nutr. 2010;19(1):91-97.
28. Pendergast DR, Di Prampero PE, Craig AB Jr, Wilson DR, Rennie DW. Quantitative analysis of the front crawl in men and women. J Appl Physiol. 1977;43(3):475-479.

29. Perez-Gomez J, Rodriguez GV, Ara I, et al. Role of muscle mass on sprint performance: gender differences? Eur J Appl Physiol. 2008;102(6):685-694.

30. Winter EM, Brookes FB, Hamley EJ. Maximal exercise performance and lean leg volume in men and women. J Sports Sci. 1991;9(1):3-13.

31. Doré E, Martin R, Ratel S, Duché P, Bedu M, Van Praagh E. Gender differences in peak muscle performance during growth. Int $J$ Sports Med. 2005;26(4):274-280.

32. Bentley DJ, Millet GP, Vleck VE, McNaughton LR. Specific aspects of contemporary triathlon: implications for physiological analysis and performance. Sports Med. 2002;32(6):345-359.

33. Millet GP, Vleck VE, Bentley DJ. Physiological differences between cycling and running: lessons from triathletes. Sports Med. 2009;39(3): 179-206.

34. Sleivert GG, Wenger HA. Physiological predictors of short-course triathlon performance. Med Sci Sports Exerc. 1993;25(7):871-876.

35. Sparks SA, Cable NT, Doran DA, Maclaren DP. Influence of environmental temperature on duathlon performance. Ergonomics. 2005; 48(11-14):1558-1567.

36. Ironman 70.3 Switzerland in Rapperswil-Jona [homepage on the Internet]. Results. Rapperswil-Jona, Switzerland: World Triathlon Corporation (WTC); c2001-2012. Available from: http://ironmanrapperswil.com/athletes/results/. Accessed 10 August, 2010.
Open Access Journal of Sports Medicine

\section{Publish your work in this journal}

Open Access Journal of Sports Medicine is an international, peer-reviewed, open access journal publishing original research, reports, reviews and commentaries on all areas of sports medicine. The manuscript management system is completely online and includes a very quick and fair peer-review system.

\section{Dovepress}

Visit http://www.dovepress.com/testimonials.php to read real quotes from published authors. 